\title{
E-Resources usage fosters Self-learning among the Engineering Student community
}

\author{
Mrs. Andhe Prafulla ${ }^{1}$, Dr. N. Chowdappa ${ }^{2}$ \\ ${ }^{1}$ Research Scholar, VTU - Visvesvaraya Technological University, Karnataka, India \\ ${ }^{2}$ Chief Librarian, BMS College of Engineering, Bengaluru, Karnataka, India \\ 'andhe.prafulla@gmail.com, \\ ²dr.nchowdappa@gmail.com,
}

\begin{abstract}
This paper presents a brief analysis of the engineering college students' e-resource usage needs vis-a-vis habits. The research analysis led to many outcomes and one of them is about the e-resource usage being a dominant factor in the particular engineering student community's self-learning process. Self-learning is attributed to be the major contribution to the academic and professional growth of a person at any point of time. The use of e-resources in and out on day to day basis is forcing the student to become self reliant and helps him to learn how to selflearn many a thing. This self-learning aspect in a student is very encouraging as waiting for an expert to actually teach them everything is time-consuming and next to impossible in this era of many student - single teacher ratio. The information spewing every second from various corners of the globe makes it necessary for each and every student to master the art of selflearning to stay abreast with the happenings in his area of study or interest. This forceful need for information search using e-resources is gradually becoming a necessity and ultimately a habit.
\end{abstract}

Keywords: e-Resources, e-Resources usage, NPTEL, Engineering Curriculum, self-learning, SWAYAM.

\section{Mrs. Andhe Prafulla}

Research Scholar, VTU - Visvesvaraya Technological University, Karnataka, India

andhe.prafulla@gmail.com,

\section{Introduction}

Today's fast paced environment demands the best from any homo sapiens. To excel in any subject area its mandatory for a person to be updated at all times. World wide web, Twitter, Blogs and other social media are full of information every other second. The information which reaches a normal person through television media or Newspaper is actually outdated by about 8 - 10 hours. So, it becomes a priority to keep abreast with the happenings worldwide through online resources and social media.

For a student the first priority with respect to information is something related to his / her education, rest is interest and need based. In this competitive world a student will obviously be lost if he/she doesn't keep themselves updated. Today's generation of students prefer to cut corners while seeking information at all times. They want the information they require very fast and with less effort. This kind of behaviour is making the current generation student a forced self-learner when it comes to e-resources usage.

\section{Literature Review}

"Self-learning" is an antique and also a present day term which never goes out of circulation. The age old books and many research papers have been browsed for studies related to this topic. The most relevant or even remotely related papers directly co-relate the eresource usage leading to self-learning which directly 
affects the student's academic performance improvement. Kothari, 1990 [1], talks about selflearning by the observation methods and interview methods elaborately represented in his book titled "Research methodologies". Ekalavya - one of the iconic example of self-learning is depicted as the better archer than Arjuna in the great Hindu Mythology "Mahabharat". He is known to have learnt everything purely by observing Guru Dronacharya teaching military arts to the princes of the royal family.

Expert opinion states that self-learning is a concept which is driven by the self-efficacy of an individual. Many a literature found and reviewed here mention self-efficacy driving self-learning and development but self-learning aiding factors as such are elusive.

Bandura, 1997 [2], in his book "self efficacy", tells about the self development of human beings through their beliefs and environments / circumstances and how it affects or structures their well-being and accomplishments subsequently.

Numerous authors have written articles on selfefficacy among students across the world and to name a few - Appleton [3] and Kuranogu [4] in 2006 and Tella, et al., in 2007 [5] etc. have all tried to emphasize the concept of the students in their particular region or country developing the self-learning ability by the changes in the environment be it the digital age or the need to educate oneself and excel or accomplish in their academics. Tella and et al., have linked the selfefficacy concept and use of e-resources to portray as the predictors of academic performance of those particular students.

Fang, L in November 2015 [6] conducted a Study on various MOOC-based Strategies from the selflearning student's perspective through changing the teacher's roles, strategies to stimulate students motivation, how to strengthen the policy guidance and finally strategies to enhance the learning environment.

Patil, Satyajit, et al. in 2017 [7] presented a case study of an one-credit, non-instructional course which was designed for the final year curriculum of the Automobile Engineering Students of the authors' esteemed Institution. This course was drafted and deployed to abet the "Lifelong learning" or self learning NBA graduate attribute (one of the 12 main graduate attributes). This course could be accessed by the students through two methods - Modular based approach and Massive Open Online Courses (MOOCs) based approach. The results of the course highlights the effective use of MOOCs for Selflearning and Choice Based Credit System by the students.

Pearson [8], the world's most leading learning company published on 18th September 2019, the results of a survey they conducted globally in the erstwhile Business World magazine Online. This survey captured the global learner's voice reflecting that education nowadays is undergoing a paradigm shift with the students taking control of their education themselves. This survey was conducted in 19 countries including India, wherein the opinion of the learners were taken regarding the primary, secondary and higher education, careers and technology. A total of 11,000 plus opinions of learners ranging from the 16 years to 70 years were taken.

The survey says that in India itself $79 \%$ believe that Self-learning will be the new self-service as you get older. Indians feel that soft skills learning and lifelong education are the need of the hour to keep themselves updated in their career life.

This concept of promoting self-learning in students of Grade 9 and above has been strongly endorsed by the Government of India with the advent of SWAYAM [9], indigenously developed by the Ministry of Human Resource Development (MHRD) and All India Council for Technical Education (AICTE) [10] long with MICROSOFT.

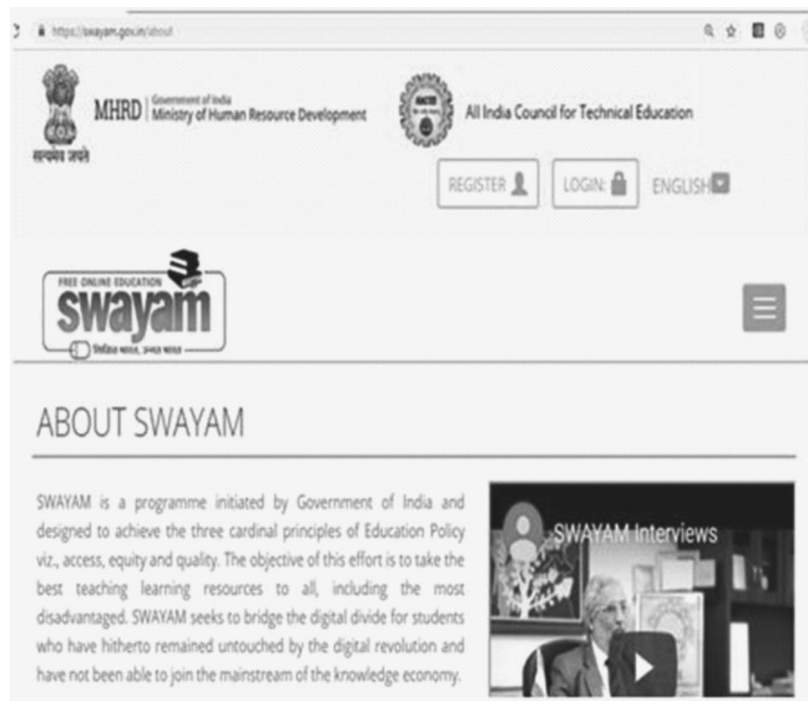

Fig. 1 : SWAYAM Homepage 
Fig. 1 and Fig. 2 show the homepage of SWAYAM depicting its scope to cover 2000 courses \& 80000 hours of learning. SWAYAM aims to cover from school to professional courses, across all the geographic boundaries and be the digital divide within India and reach out to the needy irrespective of the student, free of cost. The only investment would be access to Internet. SWAYAM reaches out to the aspiring engineering students via NPTEL (National Programme on Technology Enhanced Learning) which is captured in Fig. 3.

Apart from the Consortia and Internet which are the main driving factors of e-resource usage growth among students and the subsequent self-learning trait in students as the abundance of information makes them curious to know more and more about everything they are searching about, the credit based system for students and staff have made it more lucrative. Earlier, AICTE curriculum made 200 credits mandatory for an engineering student and recently its 150 to 160 credits earned only will ensure the Under Graduate Degree in Engineering for any student and moreover some more credits can be earned by getting certified using the online courses in NPTEL.

Courses delivered through SWAYAM are available free of cost to the learners, however students wanting certifications shall be registered, shall be offered a certificate on successful completion of the course, with a little fee. At the end of each course there will be an assessment of the student through proctored examination and the marks/grades secured in this exam could be transferred to the academic record of the students. UGC has already issued the UGC (Credit Framework for online learning courses through SWAYAM) Regulation 2016 advising the Universities to identify courses where credits can be transferred on to the academic record of the students for courses done on SWAYAM.

SWAYAM platform is indigenously developed by Ministry of Human Resource Development (MHRD) and All India Council for Technical Education (AICTE) with the help of Microsoft and would be ultimately capable of hosting 2000 courses and 80000 hours of learning covering school, under-graduate, post-graduate, engineering, law and other professional courses.

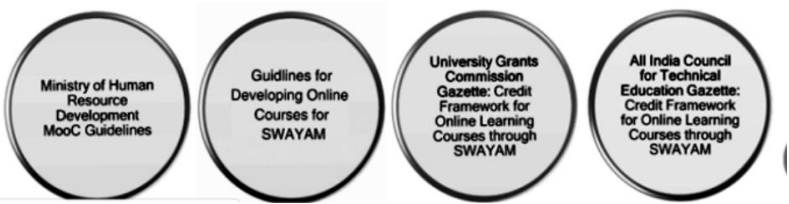

Fig. 2 : SWAYAM Homepage Continued...

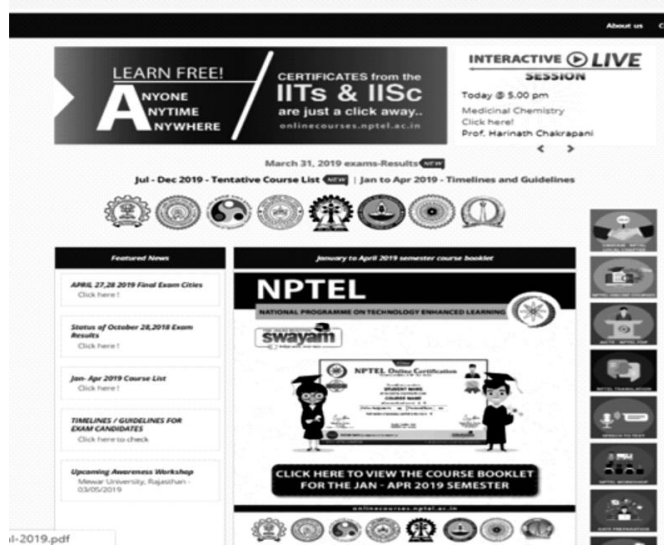

Fig. 3 : NPTEL website homepage

\section{Objectives}

- To show the prevalent usage of the E-Resources by the students of Engineering Colleges.

- To analyse the impact of E-resources usage on selflearning of the engineering college students.

\section{Scope And Limitations}

The study covers the engineering students across various age groups and engineering colleges situated only in Karnataka, India. The analysis is based on the self-declaration of the respondents to the questions given in the distributed questionnaire.

The analysis is limited to the particular concept of self-learning enumerated in this paper.

\section{Methodology}

An initial manual questionnaire was deemed tedious and not far-reaching to the target audience and hence a Google form questionnaire was formulated and sent to the respondents of 204 engineering colleges under the affiliation of VTU ( Visvesvaraya Technological University), in Karnataka through their respective librarians with an aim to analyze the eresource usage and its impact among students, viz., self-learning. A sample of 5 to 20 students using eresources per college was the target, but the various infrastructure drawbacks (internet connectivity not available, server problem), vacation time for students, geographic location (rural areas) etc. resulted in only 513 responses from 36 colleges across Karnataka, India. Out of these 513 responses, only 390 were deemed appropriate with completely filled questionnaires. Hence these questionnaires are only considered for the analysis.

This questionnaire sported questions ranging from personal details to usage methods and ended with satisfaction markings regarding the same.

Fig. 4 shows that the age of the Engineering students in first and second years are generally below 20 years, whereas the average ages of the third and fourth year students tend to be between 21-25 years category. Fig. 4 also reflects the mild presence of the research scholars, PG Students and Faculty members, who were an unexpected part of the analysis in the form of age groups 26-30, 31-35 and above 35 . 
The main focus of this research is on the students in the age groups "below 20" and between 21-25 years.

\section{Age Group (years)}

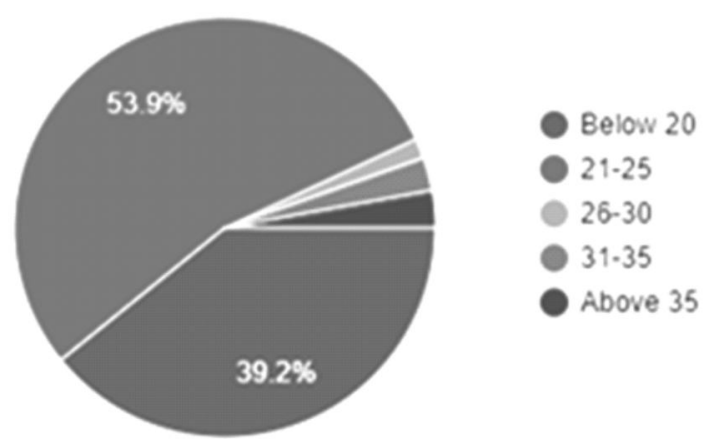

Fig. 4: Respondent's Age group

It shows the age group which clearly denotes the year in which they are studying. $39.2 \%$ of the respondents belong to the first year and second year of Engineering, that is, I, II, III and IV Semester of various engineering streams. $53.9 \%$ of the respondents using the e-resources of the library belong to the third and fourth year comprising of the V, VI, VII and VIII Semesters of Engineering.

This percentage leads to the assumption that the engineering students use the e-resources more in their third and fourth years (4 semesters) than the first and second year students combined.

Fig. 5 shows that the majority usage is by the third and fourth year students depicting their e-resource usage percentage between $37.6 \%$ and $55.9 \%$ (combination of 3 categories of users - 22\% of users using e-resources for 6 months to 1 year, $18.4 \%$ of users using the e-resources in the library for 1 to 2 years and finally $15.5 \%$ have been using the eresources between 2 to 4 years).

As per the data assimilated from the questions in the questionnaire, the first and second year students are visiting the library often for Assignments and various curriculum based information gathering. Moreover the newcomers frequent the digital library more in the initial years as the course is new and projects are not in focus. Next most frequently used student category are the third year students who are now looking at the different e-resources to help them in gaining information and knowledge to further their studies and other exams they plan so that the entrance exams for various higher studies in India or Abroad can be easily scaled when the time comes. Percentage drops based on the syllabus requirement in the course of Engineering.

\section{Experience of using the e-Resource section: How long have you been using the e-Resources section?}

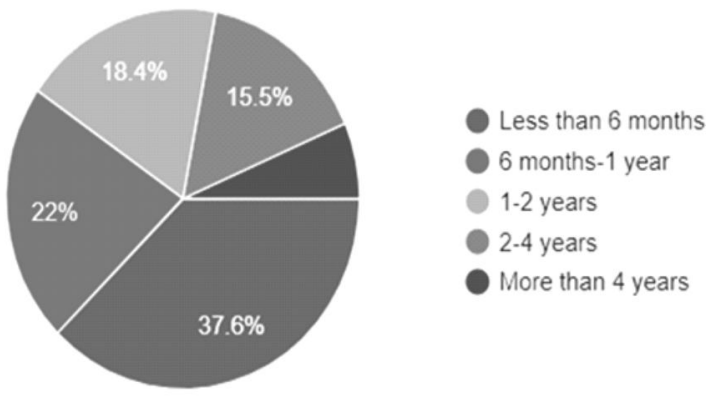

Fig. 5: E-resources Usage experience by the Engineering Students

The data shows that the final year students seem to visit the e-resource section only during the project season or internship, bringing the overall percentage to $15.5 \%$.

Apart from the regular syllabus based usage of the e-resources section, it was also observed from the questionnaire's analysis that when AICTE made the credits as 150 - 160 from the earlier 200 for a student to get an Under Graduate degree in Engineering, many students used the e-resources section to gain knowledge and self-learn the courses through SWAYAM MOOCs (Massive Open Online Courses), NPTEL etc.

Not only the Under Graduate students but also the skeletal $6.5 \%$ of Post Graduate students, Researchers and Faculty members were also highly featured in using the SWAYAM MOOCs for earning Credits.

The negligible $6.5 \%$ is the more than 4 years of usage by the outliers who are the PG students and faculty members who were not part of the survey but still were included to be taken up as another arm of research path in the future.

The filled in data by the 513 respondents was downloaded in an excel file and analyzed as shown in Fig. 6. Since all the relevant details were not filled by each student, the most relevant 390 responses were filtered and taken for analysing. 


\begin{tabular}{|c|c|c|c|c|c|c|}
\hline \multirow{2}{*}{ (2) } & Home & Page Lorou & Formulas & Review & ve & Acrobst \\
\hline & F266 & \multicolumn{5}{|c|}{ - $\quad \&$ Self instruction } \\
\hline $\bar{A}$ & A & B & c & 0 & E & $\mathrm{F}$ \\
\hline 1 & $\begin{array}{l}\text { Institution } \\
\text { Name }\end{array}$ & Student Name & $\begin{array}{l}\text { Age Group } \\
\text { (years) }\end{array}$ & $\begin{array}{c}\text { Subject / Branch } \\
\text { of study }\end{array}$ & $\begin{array}{c}\text { seme } \\
\text { ster } / \\
\text { Year }\end{array}$ & $\begin{array}{l}\text { 5.Methods of Learning to use of } \\
\text { e-Resources: How did you learn } \\
\text { to handle the e- Resources? }\end{array}$ \\
\hline 262 & KSIT & Sample 261 & Below 20 & CSE & " & $\begin{array}{l}\text { Training from university } \\
\text { /institutional library }\end{array}$ \\
\hline 263 & kSIT & Sample 262 & 21.25 & ISE & VII & Self Instruction \\
\hline 264 & BMSCE & Sample 263 & Below 20 & MECHANICAL & 1 & $\begin{array}{l}\text { Guidance from colleagues and } \\
\text { friends }\end{array}$ \\
\hline 265 & PESIT & Sample 264 & Below 20 & CIVIL & " & Training from university \\
\hline 266 & BMSCE & Sample 265 & Below 20 & MECHANICAL & 1 & Self instruction \\
\hline 267 & BMSCE & Sample 266 & Below 20 & EEE & III & Self instruction \\
\hline 268 & BMSCE & Sample 267 & 21.25 & $\mathrm{Ct}$ & $\mathrm{v}$ & Self Instruction \\
\hline 269 & kSIT & Sample 268 & Below 20 & ECE & " & Self instruction \\
\hline 270 & GSSSIETW & Sample 269 & $21 \cdot 25$ & CSE & vin & $\begin{array}{c}\text { Training from university } \\
\text { /Institutional library }\end{array}$ \\
\hline 271 & RNSIT & Sample 270 & $21 \cdot 25$ & $\pi$ & viII & $\begin{array}{l}\text { Guidance from colleagues and } \\
\text { friends }\end{array}$ \\
\hline 272 & Jss & Sample 271 & $21 \cdot 25$ & ISE & VII & Self Instruction \\
\hline 273 & RNSIT & Sample 272 & Below 20 & MED. ELE. & vi & Self instruction \\
\hline 274 & BNMIT & Sample 273 & 21.25 & EEE & $\mathrm{v}$ & Self Instruction \\
\hline 275 & BMSIT & Sample 274 & 21.25 & IEM & vi & Self Instruction \\
\hline & ACHARYA & Sample 275 & 21.25 & ECE & VII & Self Instruction \\
\hline
\end{tabular}

Fig. 6 : Questionnaire data dump

The resultant bar graphs of Fig. 7 depict the outcome of the analysis. These are purely based on the students' perception of self - learning and accomplishment.

\section{Results}

As part of the author's research, a questionnaire when distributed and collected from the Engineering College students of Karnataka, India, it was found that the e-resource usage is the major information gathering / information search tool used. The analysis of the researcher's questionnaire data collection led to the following resultant. A few parameters answered by the engineering students showed that to fulfil their academic requirements the use of the e-resources available in the Library is mandatory. Many journals like Elsevier, Taylor \& Francis, IEEE etc were available through the consortium formed by the Visvesvaraya Technological University and made available to the affiliated colleges at a nominal cost. Since it was available for the students in the college, the project work, semester wise curriculum made it easy and necessary for the student to utilize the knowledge available in the digital library. But how to use or the method of navigating the e-resources databases was self-learnt by them as per the responses given.

The significance of the initial orientation during the beginning of the year given by the librarians to the fresher students seems to be lost / not mentioned while answering the questionnaire.

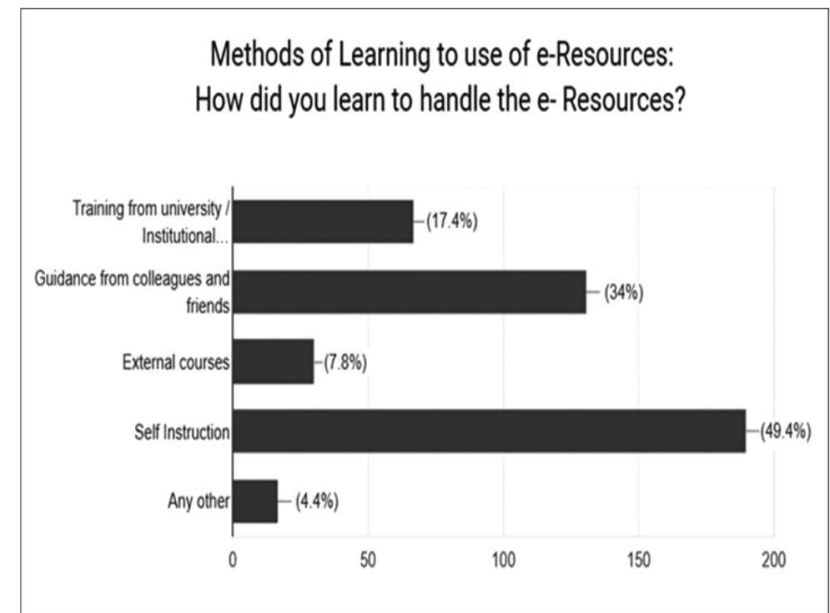

Fig. 7 : E-resource usage Learning Methods

Data in Fig. 7 emphasizes that 49.4 percent of the overall 390 users are "self-instructed". When random telephonic interviews and face to face interviews wherever possible were made based on the filled-in questionnaire, it was found that the new generation of tech-savvy student population don't need much help when given a topic to learn. They just "Google" everything. But then again, they are also clueless on how to actually pick out the relevant information from the information heap thrown at them by Google. If online searching according to the students is one thing, actually pinpointing the relevant information without wasting time is another thing. Here is where the digital librarian acts as the guiding light for the students lost in the sea of information.

Next count of 34 percent as per the graph in Fig.7, chose the option which said that they were guided by "Colleagues and friends". Here again the seniors or more experienced students come in handy for these novices who are still fresh with respect to using the eresources in the online database. Only 17.4 percent students in Fig. 7 mention that they have received the "training from University or Institutional Library". However, the long term usage of the e-resources tends to make the respondents give less weightage to the initial awareness program / guidance provided to them. The human tendency is prevalent in this case where the more they learn the faster they forget the roots / sources.

7.8 percent students maintain that they learnt the eresources usage by attending "External Courses" which turned out to be the coaching classes on computer and other subjects they attend outside of their curriculum. 4.4 percent said "any other" means of learning to use the e-resources. Here the term "any 


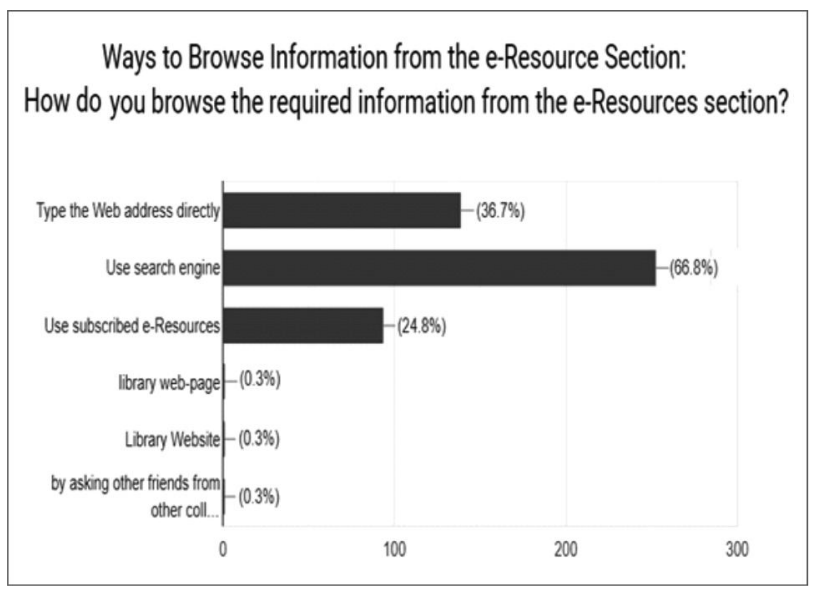

Fig. 8 : Methods of searching for using e-resources

other" when investigated turned out to be the help taken by the students from their siblings and / or parents.

The prevalent usage of e-resources has made the current engineering college student so much selfreliant that they want more information than provided. Hence while checking for information online for their academic needs, Fig. 8 shows statistics which emphasizes the self-learning aspect of the student while using the e-resources day in and day out. As per the graph in Fig. 8, only 24.8 percent of the students go only to Subscribed e-resource databases for their educational and research needs. These are made freely available to the students through the consortia formed by the University. Majority of the students, that is, 66.8 percent of the surveyed population use the search engine to check out the e-resources available freely online. These students again when interviewed opined that when they browse the subscribed eresources they are plagued with so many doubts and clarifications that they are forced to check out the internet for more validation and authentication of the matter gathered. Many a times when information is not available online, they check out the conventional documents in the library for the same.

About 36.7 percent of them go to the website directly for information. These students are wellversed in the search methodologies and have been using these particular websites for information for a longer period of time. Hence they directly use the website. For example, the students use the NPTEL website for more information on a particular topic. The other three parameters like browsing the library webpage, library websites, asking other friends from other colleges are redundant with their negligible 0.3 percent emulating to 1 response each. The e-resource usage leads to self-learning due to the abundant information available and the impact lies on the deviations taken by the students to search and use the e-resources.

\section{Conclusion}

The agencies of higher education like UGC, AICTE and the Universities in collaboration with the Ministry of Human Resource Development of India are striving to make information cheaper and more accessible to the students with their constant efforts and consortia formation. It is observed that an average student would seek information through notes from seniors / teachers / outside agencies rather than spending time using the e-resources in the Institution library or through remote access of e-resources. They don't realize that they are getting lost in the vast sea of irrelevant and excess information available online, which is what they get, while searching for a particular topic on the Internet.

All the Universities across the country should make it mandatory for the constituent colleges to subscribe and provide free e-resources to students the usage increases and benefit to the students is that their self-learning concept increases. The study further proposes that increasing the percentage of selflearning component in the syllabi it is directly proportional to the increase in the e-resources usage by students.

The resultant analysis shows that the percentage of e-resources usage has increased from $37 \%$ to $59 \%$ from I to III year students as it was made mandatory by the corresponding syllabi. The analysis further proves that if the usage of e-resource is made mandatory (with high quality and mandatory subscription to VTU consortia by 219 colleges) availability ensures increased e-resource usage as shown by the survey.

Colleges and Universities are trying to promote eresources usage through their Libraries as the professional staff are trained to guide the students to the right information and in the right direction. Of the various sources of learning to use the existing eresources, viz., training given by the library professionals; Guidance from colleagues etc, it is found that self instruction methodology is the major contributing factor. The increased and consistent usage of e-resources tends to make the user more and 
more self-reliant, thereby forgetting the source bases of Internet usage learning received in their beginner days.

To confirm the trends obtained above because of the mandatory syllabi, further survey could be carried after a few more graduation cycles covering a few more universities across other states.

\section{References}

Books

[1] Kothari, C R. (2004) "Research Methodology: Methods and Techniques". 2nd ed. New Delhi: New Age International Publisher.

[2] Bandura, A. (1997) "Self-efficacy: The exercise of Control".- New York: Cambridge University Press.

Journal Articles

[3] Appleton, Leo. (2006) "Perception of electronic library resources in further education" in "The Electronic library", Vol. 24 (5): p.619-634.

[4] Kuranogu, Serap S, Kukoyunlu, Buket and Umay Aysum. (2006) "Developing the information literacy self efficacy scale" in "Journal of Documentation", Vol. 62 (6): p.730 - 743

[5] Tella, Adeyinka and et al. (2007) "Self Efficacy and use of Electronic Information as Predictors of
Academic Success" in "Electronic Journal of Academic and Special Librarianship", Summer; Vol. 8(2).

Articles with DOI

[6] Fang, L. (2015, November). A Tentative Study on MOOC-based Strategies of College Students' Self-Learning Ability. In 2015 10th International Conference on P2P, Parallel, Grid, Cloud and Internet Computing (3PGCIC) (pp. 865-867). IEEE.

DOI: 10.1109/3PGCIC.2015.45

[7] Patil, Satyajit, et al. (2017). Adopting MOOC Based Approach for 'Self-Learning' of Students. Journal of Engineering Education Transformations, 30(3), 310-315.

DOI: $10.16920 /$ jeet/2017/v30i3/110606

Magazine Article

[8] Pearson, (2019, September 18th). "50\% Of Learners In India Use Internet For Self-Studies: Survey". Business World Online.

Official Websites

[9] https://swayam.gov.in/- SWAYAM WEBSITE

[10] https://www.aicte-india.org/ - AICTE WEBSITE 